\title{
New strategies for lowering the costs of antiretroviral treatment and care for people with HIVIAIDS in the United Kingdom
}

This article was published in the following Dove Press journal:

ClinicoEconomics and Outcomes Research

II July 2012

Number of times this article has been viewed

\author{
Brian Gazzard' \\ Christiane Moecklinghoff ${ }^{2}$ \\ Andrew Hill ${ }^{3}$ \\ 'St Stephens Centre, Chelsea and \\ Westminster Hospital, London, \\ UK; ' Janssen, Neuss, Germany; \\ ${ }^{3}$ Department of Pharmacology \\ and Therapeutics, University \\ of Liverpool, UK
}

\begin{abstract}
In the UK, the annual cost of treatment and care for people with human immunodeficiency virus (HIV)/acquired immune deficiency virus (AIDS) rose by over $600 \%$ from $£ 104$ million in 1997 to $£ 762$ million in 2010; approximately two-thirds of the $£ 762$ million cost of treatment and care in 2010 was for the procurement of antiretrovirals and other related drugs. The number of people accessing care for HIV/AIDS rose from 22,000 in 2000 to 65,000 in 2009. Adoption of "test and treat" guidelines for treating all HIV-infected people with antiretrovirals would further increase the burden of costs. Given the current economic situation, there is now a new focus on strategies for treatment and care of people with HIV-1 infection which can maintain efficacy but at a lower cost. In this review, we propose three strategies which could potentially lower the costs of treatment and care, ie, stopping testing CD4 counts for patients with full HIV RNA suppression on antiretroviral treatment and recent CD4 counts above 350 cells $/ \mu \mathrm{L}$; more widespread use of generic antiretrovirals as replacements for patients currently taking patented versions; and use of darunavir-ritonavir monotherapy as a switch option for patients with full HIV RNA suppression on other antiretrovirals and no history of virological failure. However, it is important that high standards of clinical care are maintained despite cost-saving measures. Antiretrovirals with generic alternatives may have toxicity issues, eg, zidovudine and nevirapine. There could be ethical issues in starting patients on these drugs if they are currently tolerating other treatments. The use of darunavir-ritonavir monotherapy is not consistently recommended in international HIV treatment guidelines.
\end{abstract}

Keywords: health economics, generics, darunavir-ritonavir monotherapy, nucleoside analogs, non-nucleoside reverse transcriptase inhibitors

\section{Introduction}

In the UK, the annual cost of treatment and care for people with human immunodeficiency virus (HIV)/acquired immune deficiency virus (AIDS) rose by over $600 \%$ from $£ 104$ million in 1997 to $£ 762$ million in 2010; approximately two-thirds of the $£ 762$ million cost of treatment and care in 2010 was for the procurement of antiretrovirals and other related drugs. ${ }^{1}$ The number of people accessing care for HIV/AIDS rose from 22,000 in 2000 to 65,000 in $2009 .^{2}$ In 2000, there were an estimated 14,000 people receiving antiretroviral treatment in the UK; by 2009, this number had risen to 51,000. In 2010, there were 6750 people newly diagnosed with HIV infection in the UK compared with 500 HIV-related deaths. During the past 10 years, there has been a linear rise in the number of people diagnosed with HIV in the UK and starting antiretroviral treatment, with no sign of a plateau. ${ }^{2}$ If current trends continue, we can
Correspondence: Andrew Hill

Department of Pharmacology and Therapeutics, University of Liverpool, 70 Pembroke Place, Liverpool L69 3GF, UK

Tel +447834364608

Fax +442086751716

Email microhaart@aol.com 
expect the number of people needing antiretroviral treatment in the UK to continue to grow for the next 5-10 years.

It is also important to note that of the 90-100,000 people estimated to be infected with HIV in the UK in 2012, 26\% are unaware of their infection. ${ }^{2}$ New efforts to test people for HIV infection on an "opt-out" basis, either during antenatal care or if presenting with key indicator illnesses, will likely identify even more people in need of treatment.

In Europe, the current recommendation is to start antiretroviral treatment if the CD4+ T cell count is below 350 cells $/ \mu \mathrm{L}$ or if the patient is symptomatic. ${ }^{3,4}$ In the US, there is a move to recommend starting antiretroviral treatment for all patients, regardless of CD4 cell count. ${ }^{5}$ Evidence from large cohort studies supports the earlier initiation of antiretroviral treatment: people who are successfully treated with antiretrovirals are now predicted to have a near-normal lifespan, but must remain on antiretrovirals for life. ${ }^{6}$ In addition, the risk of sexual transmission of HIV is reduced by over $90 \%$ if infected people are treated. ${ }^{7}$ If adopted in the UK, increased HIV testing and earlier initiation of treatment will further increase the number of patients taking antiretrovirals and associated costs.

International HIV treatment guidelines recommend first-line treatment with two nucleoside analogs and either a non-nucleoside or a boosted protease inhibitor. ${ }^{3-5}$ When patients have achieved full HIV RNA suppression below assay detection limits, there may be switches to different antiretrovirals to improve tolerability or convenience. If there is virological failure, with emergence of drug resistance, second-line treatment tends to be more complex, and normally includes a protease inhibitor and new drug classes, such as integrase inhibitors, CCR5 antagonists, or secondgeneration non-nucleosides..$^{3-5}$

Given the current economic pressures on the UK National Health Service, there is a need to find ways to lower the costs of HIV treatment and care while maintaining the highest medical standards. In this review, we assess the costs of antiretroviral treatment and diagnostics, and suggest ways in which the costs may be reduced. The overall impact of these measures on national budgets may be sufficient to allow more patients to be treated, while maintaining current funding levels. Three key areas are assessed, ie, rational use of diagnostic testing, use of generic drugs after patent expiry, and use of less intensive treatments for patients with full HIV RNA suppression, such as protease inhibitor monotherapy. These measures could potentially be adopted in other countries with similar pricing structures for antiretroviral treatment and diagnostics.

\section{Rational use of diagnostic testing}

Once HIV antibody testing has identified a patient as HIV-infected, CD4+ T cells counts are used to help decide which patients should be started on antiretroviral treatment. International HIV treatment guidelines may include a CD4 threshold for the initiation of treatment, such as below 350 cells $/ \mu \mathrm{L} .{ }^{3,4}$ If CD4 counts are close to or below the threshold of 200 cells/ $\mu \mathrm{L}$ during antiretroviral treatment, continued monitoring for CD4 counts can help to identify those needing prophylaxis for opportunistic infections. ${ }^{8}$ Patients with CD4 counts below 200 cells/ $\mu \mathrm{L}$ are at higher risk of opportunistic infections, and this correlation is consistent across different antiretroviral classes. ${ }^{9}$

During antiretroviral treatment, the main measure of success is suppression of HIV RNA levels below 50 copies $/ \mathrm{mL}$; sustained suppression of HIV RNA leads to rises in CD4 count and improved survival, particularly if the CD4 count has risen above 350 cells/ $\mu$ L. ${ }^{9,10}$ HIV RNA suppression also correlates with a reduced chance of HIV transmission. ${ }^{7} \mathrm{By}$ contrast, the CD4 count is a poor measure of success on treatment, with low sensitivity or specificity to detect virological failure or emergence of drug resistance. ${ }^{11,12}$

When the CD4 count rises above 350 cells/ $\mu \mathrm{L}$ after full HIV RNA suppression, the value of continuing monitoring of CD4 counts may be limited. European and US treatment guidelines are now recommending less frequent monitoring for CD4 counts (every 6-12 months) if patients have full HIV RNA suppression. ${ }^{3-5}$

Continued HIV RNA suppression is a strong predictor of high and rising CD4 counts. ${ }^{13}$ In the Royal Free Hospital cohort study, ${ }^{14}$ patients who had HIV RNA suppression below 50 copies/mL during antiretroviral treatment and CD4 counts above 500 cells/ $\mu \mathrm{L}$ were followed up while HIV RNA suppression was maintained. None of the patients showed sustained reductions in CD 4 count below 350 cells/ $\mu \mathrm{L}$ while the HIV RNA level remained suppressed below 50 copies $/ \mathrm{mL}^{14}$ Similar results were found in the SMART (Strategies for Management of Anti-Retroviral Therapy) study. ${ }^{15}$

In the UK, the number of patients treated with antiretrovirals is approximately 51,000 . If we assume that at least $70 \%$ of these patients have full HIV RNA suppression and CD4 counts above 350 cells $/ \mu \mathrm{L}$, then the potential cost savings from stopping CD4 testing can be calculated. The cost of a CD4 test in the UK is approximately $£ 80$, including the costs of laboratory infrastructure and staffing. ${ }^{14}$ Approximately $70 \%$ of the 51,000 people treated with antiretrovirals in the UK have HIV RNA less than 50 copies/mL and CD4 counts above 350 cells $/ \mu \mathrm{L} .{ }^{16} \mathrm{~A}$ small proportion of these patients 
would need to be retested for CD4 counts if high-level rebound in HIV RNA was detected, and the proportion would be no more than $5 \%$ per year. ${ }^{16}$ If the remaining 34,000 patients were no longer tested for CD4 counts, the potential saving would be approximately $£ 5.4$ million per year. In addition, if $\mathrm{CD} 4$ counts are the main guide to starting antiretroviral treatment in treatment-naïve patients, it may be worth evaluating whether treatment-naïve patients need regular testing for HIV RNA, if the initial levels are low.

\section{Introduction of generic antiretrovirals}

By the end of 2011, the original 20-year patents had expired for several antiretrovirals. ${ }^{17}$ The most important of these are zidovudine, lamivudine, and nevirapine. The original patents have also expired for stavudine, didanosine, saquinavir, and indinavir, but these are no longer widely used in developed countries. Generic versions of zidovudine and lamivudine are already available in the UK. In 2013, generic versions of nevirapine are expected to be introduced into the UK, with generic versions of efavirenz arriving soon afterwards. These non-nucleosides are used widely in first-line antiretroviral treatment.

Table 1 shows the list prices of the patented drugs from the British National Formulary. ${ }^{18}$ These are only a guide to the true costs of treatment paid by local health authorities. The prices of generic drugs can also change over time, depending

Table I Published unit costs of commonly used antiretrovirals in the UK*

\begin{tabular}{|c|c|c|}
\hline Drug & Dose & Cost per year \\
\hline \multicolumn{3}{|l|}{ Nucleoside analogs } \\
\hline Abacavir & $600 \mathrm{mg}$ OD & $£ 2699$ \\
\hline Lamivudine & $300 \mathrm{mg}$ OD & $£ 2034$ \\
\hline Emtricitabine & $200 \mathrm{mg}$ OD & $£ 1989$ \\
\hline Tenofovir & $300 \mathrm{mg}$ OD & $£ 3103$ \\
\hline Didanosine & $400 \mathrm{mg}$ OD & $E|99|$ \\
\hline Zidovudine & $250 \mathrm{mg}$ BID & $£ 2025$ \\
\hline \multicolumn{3}{|l|}{ Non-nucleosides } \\
\hline Nevirapine & $200 \mathrm{mg}$ BID & $£ 1946$ \\
\hline Efavirenz & $600 \mathrm{mg}$ OD & $£ 2535$ \\
\hline Etravirine & 200 mg BID & $£ 3891$ \\
\hline \multicolumn{3}{|l|}{ Protease inhibitors } \\
\hline Atazanavir-ritonavir & $300 / 100 \mathrm{mg}$ OD & $£ 4250$ \\
\hline Darunavir-ritonavir & $800 / 100 \mathrm{mg}$ OD & $£ 4033$ \\
\hline Lopinavir-ritonavir & $400 / 100$ mg BID & $£ 3739$ \\
\hline Saquinavir-ritonavir & $1000 / 100$ mg BID & $£ 4063$ \\
\hline \multicolumn{3}{|l|}{ Other drug classes } \\
\hline Raltegravir & $400 \mathrm{mg}$ BID & $£ 7875$ \\
\hline Maraviroc & $300 \mathrm{mg}$ BID & $£ 6705$ \\
\hline
\end{tabular}

Note: *Value-added tax (VAT) excluded.

Abbreviations: OD, once daily; BID, twice daily.

on the volumes of orders available and the competition between different generic companies. A generic version of zidovudine is available ${ }^{19}$ priced at $£ 591$ per person-year (versus $£ 2025$ for the branded version). Also a generic version of lamivudine is available for $£ 547$ per personyear, versus $£ 2034$ for the branded version. ${ }^{19}$ There are similar differences between originator and generic prices of zidovudine and lamivudine in Spain. ${ }^{20}$ Generic nevirapine has not yet been introduced into the UK, but a generic price of $£ 839$ per person-year has been announced. ${ }^{21}$ These generic prices for the UK are far higher than in sub-Saharan Africa, where the cost of triple combination treatment (eg, zidovudine-lamivudine-nevirapine) can be as low as $£ 100$ per person-year. ${ }^{17}$ However, there should be potential for generic HIV drug prices to fall in the UK, if this market becomes larger over time.

Table 2 shows the potential costs of triple combination treatment in the UK, using published list prices. ${ }^{18}$ Based on list prices alone, the combinations of two nucleoside analogs with a non-nucleoside are cheaper than combinations of two nucleosides with a boosted protease inhibitor. Of the nucleoside analogs, tenofovir and abacavir are most widely recommended in treatment guidelines; zidovudine shows strong efficacy in triple combination treatment, but hematological toxicity and nausea can lead to discontinuation of treatment. Emtricitabine and lamivudine are closely related nucleoside analogs, and have shown similar efficacy in randomized trials. Of the non-nucleosides, efavirenz is more widely recommended than nevirapine in treatment guidelines, ${ }^{3-5}$ but nevirapine can be used as a switch option for patients with HIV RNA suppression; using the drug in

Table 2 Costs of combination antiretroviral treatments in the UK*

Drug Costs per person-year
(number of pills/day)

\section{NRTI-NNRTI combinations}

Abacavir + lamivudine + nevirapine

Tenofovir + emtricitabine + efavirenz

Zidovudine + lamivudine + nevirapine

Zidovudine + lamivudine + efavirenz

\section{NRTI-PI combinations}

Abacavir + lamivudine + darunavir-ritonavir

Tenofovir + emtricitabine + darunavir-

ritonavir

Tenofovir + emtricitabine + atazanavir-

ritonavir

PI monotherapy

Darunavir-ritonavir 800/100 mg OD

Note: *Value-added tax (VAT) excluded.

Abbreviations: PI, protease inhibitor; OD, once daily; NNRTI, non-nucleoside reverse transcriptase inhibitor; NRTI, nucleoside reverse transcriptase inhibitor.
$£ 6496(3)$

$£ 7627$ ( 1 )

$£ 5822(4)$

$£ 8766$ (4)

$£ 9115(4)$

$£ 8983(3)$

$£ 4033(3)$ 
this way may lessen the risk of severe rash, which is the most important side effect of this non-nucleoside.

Of the protease inhibitors, darunavir-ritonavir and atazanavir-ritonavir are the most widely recommended, owing to their once-daily dosing and favorable efficacy and safety profiles versus lopinavir-ritonavir shown in randomized trials. ${ }^{22,23}$

The most widely used antiretrovirals with the potential for replacement by generics are zidovudine, lamivudine, and nevirapine. The most easily replaced drug would be lamivudine, used by a high proportion of people treated for HIV infection; emtricitabine could also potentially be replaced by lamivudine, given that these drugs are very closely related.

However, zidovudine is no longer recommended in UK treatment guidelines, owing to an excess risk of lipoatrophy compared with using either abacavir or tenofovir. ${ }^{24,25}$ Zidovudine is also associated with anemia, neutropenia, and nausea. ${ }^{24,25}$

Likewise, the use of nevirapine is associated with a risk of life-threatening rash and hepatotoxicity, which can be life-threatening. ${ }^{26,27}$ Switches from patented to generic versions of nevirapine are unlikely to cause additional adverse events, if the drug levels are bioequivalent between the two formulations. However, if patients were switched from other antiretrovirals to generic nevirapine for cost reasons, the risk of life-threatening hepatotoxicity and rash cannot be excluded. ${ }^{26,27}$

The switch to generic use of zidovudine or nevirapine may be restricted to those already taking patented versions of these drugs. Based on the difference between the list prices and generic prices, switching 1000 patients from branded supplies of zidovudine to the generic version would save $£ 1.4$ million per year, while switching 1000 patients from patented to generic versions of nevirapine would save $£ 1.1$ million per year.

These calculations need to be interpreted with care. The prices of the generic drugs are not yet fixed, and may decrease over time, with higher volumes and competition between generic companies. In addition, the pill burden is likely to be higher for combinations of generic drugs, which are not normally coformulated (patent protection is still in force for coformulations such as zidovudine-lamivudine or abacavir-lamivudine). There are strict regulatory requirements for quality and bioequivalence of generic antiretrovirals, which any generic company needs to adhere to if their drugs are to be sold in the UK.

Expiry of the UK patent for efavirenz is expected in 2013 , but the patent on the fixed dose combination of tenofovir, emtricitabine, and efavirenz will remain in place until 2026. ${ }^{17}$ Generic versions are expected to be imported soon afterwards. Efavirenz is widely recommended across treatment guidelines ${ }^{3-5}$ and generic versions have the potential for widespread use, unlike generic nevirapine or zidovudine. The minimum price of generic efavirenz in low-income countries is US \$55 (£36) per person-year of treatment, versus the UK list price of $£ 2535$ per person-year of treatment (Table 1). However, it is unclear what prices will be set by generics companies importing efavirenz into the UK. A more detailed analysis of potential cost savings needs to be conducted, after the generic prices of efavirenz have been set.

\section{Use of protease inhibitor monotherapy}

For over 15 years, the standard of care for HIV treatment has been the use of at least three antiretrovirals, typically two nucleoside analogs combined with either a non-nucleoside or a boosted protease inhibitor. Three recently conducted randomized clinical trials, ie, MONET (MONotherapy in Europe with TMC114), ${ }^{28}$ MONOI, ${ }^{29}$ and MONARCH (MONotherapy: Analysis of Reactivity and Cardiovascular Harm),${ }^{30}$ with a combined sample size of 500 patients treated for a median of 2 years, have shown that, in virologically suppressed patients, switching to darunavir-ritonavir as monotherapy can maintain HIV RNA suppression and CD4 counts, compared with standard triple combination treatment. In the MONET and MONOI trials, there was a slightly higher risk of elevations in HIV RNA for patients taking darunavirritonavir as monotherapy. ${ }^{28,29}$ However, these elevations in HIV RNA were not associated with treatment-emergent drug resistance; HIV RNA levels could be resuppressed below detection limits in almost all of these patients after reintensification with nucleoside analogs, or in many patients who continue darunavir-ritonavir monotherapy unchanged. In an analysis of the efficacy data looking at overall outcomes at the end of the MONET trial, the percentage of patients with HIV RNA $<50$ copies $/ \mathrm{mL}$ at 3 years was $83.5 \%$ in the darunavir-ritonavir monotherapy arm versus $82.2 \%$ in the triple therapy arm. No patients in either arm developed phenotypic resistance to darunavir. ${ }^{28}$ Similar results were seen after 2 years of treatment in the MONOI trial ${ }^{29}$ and after 48 weeks of randomized treatment in the MONARCH trial. ${ }^{30}$

There is the potential for substantial cost savings from the use of darunavir-ritonavir monotherapy, if nucleoside analog treatment can be stopped in the large subset of UK patients who have baseline characteristics similar to those of the three clinical trials described above: HIV RNA suppression below 50 copies/mL, baseline CD4 counts above 200 cells $/ \mu \mathrm{L}$, and no history of virological failure. Figure $1 \mathrm{~A}$ and $\mathrm{B}$ show the 


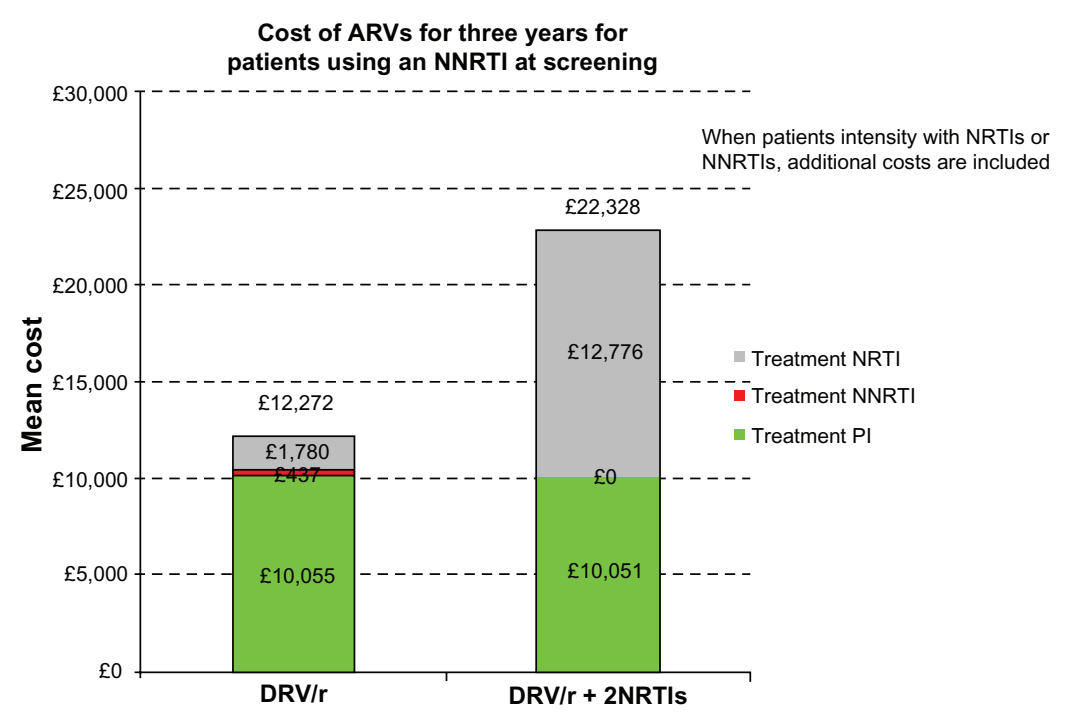

Figure IA Total cost of DRV/r or DRV/r + 2NRTIs in the MONET trial (patients taking 2NRTI/NNRTI at screening).

Abbreviations: ARV, antiretroviral; PI, protease inhibitor; NNRTI, non-nucleoside reverse transcriptase inhibitor; NRTI, nucleoside reverse transcriptase inhibitor; DRV/r, darunavir-ritonavir; MONET, MONotherapy in Europe with TMCII4.

costs of 3 years of antiretroviral treatment in the MONET trial. Figure 1A shows the costs of antiretrovirals during the trial for people who were taking non-nucleoside reverse transcriptase inhibitor-based treatment at screening, and then switched onto either darunavir-ritonavir monotherapy or darunavir-ritonavir and two nucleoside reverse transcriptase inhibitors during the trial. Figure $1 \mathrm{~B}$ shows the equivalent costs of antiretrovirals for patients who had been taking protease inhibitor-based treatment before the MONET trial. These figures are based on use of all antiretrovirals at their original list prices. There is a large saving in costs in the darunavir-ritonavir arm from stopping use of nucleoside analogs.
In a previous analysis of the MONET trial after 2 years of treatment, it was estimated that 20,000 people with HIV infection in the UK may be in this category. ${ }^{31}$ Table $3 \mathrm{~A}$ shows summary costs of antiretroviral treatment before and during the MONET trial for 20,000 patients, using the data on treatment usage from the trial itself. This analysis first summarizes the costs of the antiretroviral treatment taken before the trial for patients taking two nucleoside analogs plus either a nonnucleoside or a protease inhibitor. Non-nucleoside-based treatment is typically cheaper than protease inhibitor-based treatment, so these two groups were analyzed separately. These costs before the trial were then compared with the costs of darunavir-ritonavir during the trial, including any

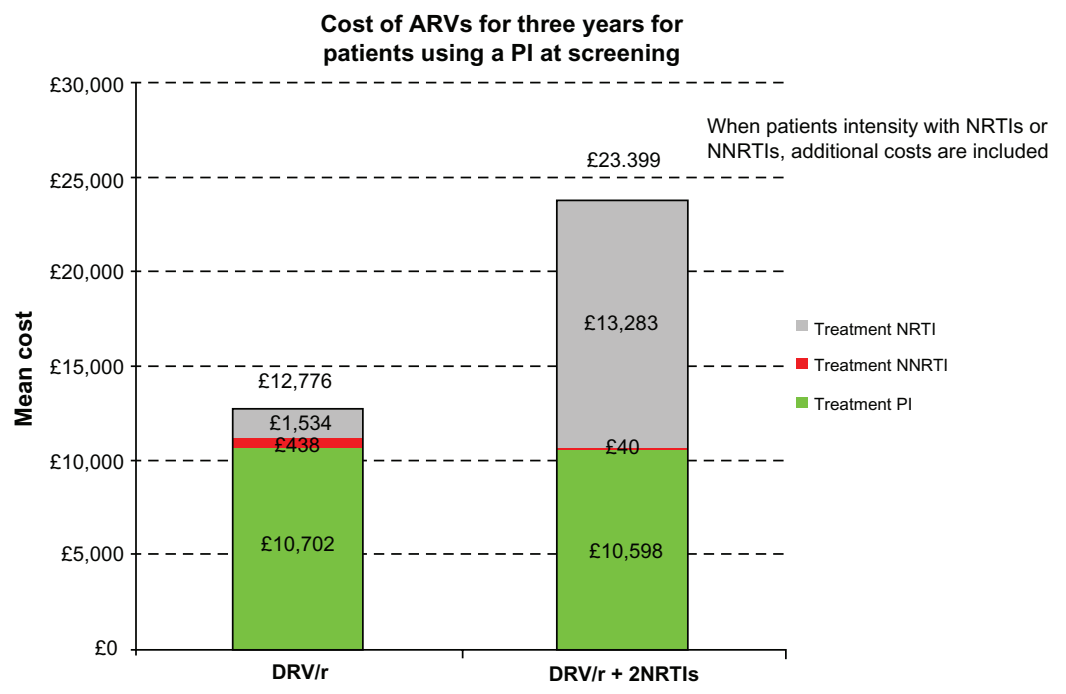

Figure I B Total cost of DRV/r or DRV/r + 2NRTIs in the MONET trial (patients taking $2 \mathrm{NRTI}+\mathrm{PI}$ at screening).

Abbreviations: ARV, antiretroviral; PI, protease inhibitor; NNRTI, non-nucleoside reverse transcriptase inhibitor; NRTI, nucleoside reverse transcriptase inhibitor; DRV/r, darunavir-ritonavir; MONET, MONotherapy in Europe with TMCII4. 
Table 3A Cost of treating 20,000 people with triple combination treatment versus darunavir-ritonavir monotherapy over three years, based on UK list prices

\begin{tabular}{|c|c|c|c|}
\hline & \multicolumn{3}{|l|}{ Prior treatment } \\
\hline & 2NRTI-NNRTI & 2NRTI + PI & Overall \\
\hline Percentage & $70 \%$ & $30 \%$ & \\
\hline Number of patients & 14,000 & 6000 & 20,000 \\
\hline \multicolumn{4}{|c|}{ Before switch to DRV/r monotherapy } \\
\hline $\begin{array}{l}\text { Three-year cost } \\
\text { per patient }\end{array}$ & $£ 19,623$ & $£ 22,818$ & $£ 20,582$ \\
\hline Total three-year cost & $£ 274.7$ million & fI36.9 million & f4II.6 millior \\
\hline \multicolumn{4}{|c|}{ After switch to DRV/r monotherapy } \\
\hline $\begin{array}{l}\text { Three-year cost } \\
\text { per patient }\end{array}$ & $£ \mid 2,272$ & $£ \mid 2,776$ & $£ \mid 2,423$ \\
\hline Total three-year cost & fI7I.8 million & $£ 76.7$ million & $£ 248.5$ millior \\
\hline Budget impact & & & \\
\hline $\begin{array}{l}\text { Total cost savings } \\
\text { over three years }\end{array}$ & fl02.9 million & $£ 60.3$ million & fI63.2 millio \\
\hline
\end{tabular}

Abbreviations: Pl, protease inhibitor; OD, once daily; NNRTI, non-nucleoside reverse transcriptase inhibitor; NRTI, nucleoside reverse transcriptase inhibitor; $\mathrm{DRV} / \mathrm{r}$, darunavir-ritonavir.

additional costs of intensification with nucleoside analogs in patients with elevations of HIV RNA.

The results from this analysis are shown in Table 3A. Before the MONET trial, the mean annual cost of antiretrovirals was $£ 6413$ for patients on non-nucleoside-based treatment, and $£ 7606$ for patients on protease inhibitor-based treatment. During the MONET trial, the mean annual perpatient cost of antiretrovirals was $£ 7780$ in the triple therapy arm, of which $56 \%$ was from nucleoside reverse transcriptase inhibitors and $44 \%$ from protease inhibitors. The mean perpatient cost in the darunavir-ritonavir monotherapy arm was $£ 4167$. We assumed that there are 51,000 people treated with antiretrovirals in the UK ( $70 \%$ non-nucleoside reverse transcriptase inhibitor-based, $30 \%$ protease inhibitor-based), and $40 \%$ of patients (approximately 20,000) meet the entry criteria for the MONET trial. A switch to darunavir-ritonavir monotherapy could cut the 3-year cost of antiretroviral treatment for these patients, from $£ 412$ million to $£ 248$ million per year, representing a saving of $£ 163$ million (Table $3 \mathrm{~A}$ ). This calculation also assumed that all drugs were costed at their UK list price. In a sensitivity analysis, we assumed $100 \%$ introduction of generic drugs where possible, with prices as shown in Table 1. In this scenario, the saving over 3 years was still $£ 53$ million pounds (Table 3B).

The combined results shown in Tables $3 \mathrm{~A}$ and B show the overall cost savings from generics and darunavir-ritonavir for the 20,000 patients in the UK who would meet the eligibility criteria of the MONET trial. The cost of treating these patients, over 3 years, was reduced from $£ 412$ million
Table 3B Cost of treating 20,000 people with triple combination treatment versus darunavir-ritonavir monotherapy over three years, based on UK list prices with 100\% generic replacement**

\begin{tabular}{|c|c|c|c|}
\hline & \multicolumn{3}{|l|}{ Prior treatment } \\
\hline & 2NRTI-NNRTI & 2NRTI + PI & Overall \\
\hline Percentage & $70 \%$ & $30 \%$ & \\
\hline Number of patients & 14,000 & 6000 & 20,000 \\
\hline \multicolumn{4}{|c|}{ Before switch to DRV/r monotherapy } \\
\hline $\begin{array}{l}\text { Three-year cost } \\
\text { per patient }\end{array}$ & $f \mid 2,740$ & $£ \mid 7,965$ & $E \mid 4,308$ \\
\hline Total three-year cost & ŁI78.4 million & Ł107.8 million & $£ 286.2$ million \\
\hline \multicolumn{4}{|c|}{ After switch to DRV/r monotherapy } \\
\hline $\begin{array}{l}\text { Three-year cost } \\
\text { per patient }\end{array}$ & $\{\mid 1,472$ & $E \mid 2,172$ & $f \mid 1,682$ \\
\hline Total three-year cost & fl 60.6 million & $£ 73.0$ million & $£ 233.6$ million \\
\hline \multicolumn{4}{|l|}{ Budget impact } \\
\hline $\begin{array}{l}\text { Total cost savings - } \\
\text { three years }\end{array}$ & ŁI7.8 million & $£ 34.8$ million & $£ 52.5$ million \\
\hline
\end{tabular}

Notes: **Assumes that all patients taking lamivudine, zidovudine, or nevirapine are switched to the generic versions. In addition, all patients taking emtricitabine are switched to generic lamivudine.

Abbreviations: PI, protease inhibitor; NNRTI, non-nucleoside reverse transcriptase inhibitor; NRTI, nucleoside reverse transcriptase inhibitor; DRV/r, darunavir-ritonavir.

to $£ 234$ million, representing a saving of $£ 178$ million, by switching patients to darunavir-ritonavir monotherapy and intensifying with nucleoside analogs where necessary, using generic versions where possible.

\section{Conclusion}

Given the current economic situation, there is now a new focus on strategies for treatment and care of people with HIV-1 infection which can maintain efficacy but at a lower cost. These efforts are aiming to minimize the budget impact of treatment and care for the rising numbers of HIV-infected people in the UK. The results from these analyses suggest that substantial cost-savings may be possible from the combination of rational use of diagnostic testing, introduction of generic antiretrovirals, and switching patients with full HIV RNA suppression to darunavir-ritonavir monotherapy.

There is now strong evidence that HIV RNA suppression is a marker of sustained rises in CD4 count during antiretroviral treatment. If patients have high CD4 counts on antiretroviral treatment, there is a justification to stop testing for CD4 as long as HIV RNA levels remain suppressed. However, it may be necessary to continue to study this issue in specialized cohort studies, to see if there are other $\mathrm{T}$ cell subsets which could provide additional information to help patient management.

Replacing branded drugs with bioequivalent generic versions could potentially save money from the UK HIV 
treatment budget. The analyses in this report are based on comparisons of published list prices and generic prices. For more accurate estimates of cost savings, these analyses would need to be repeated at the local level. However, the market for generic versions of HIV drugs is at its early stages in the UK, and prices should fall further if there is competition for market share between generic companies. If patients are already receiving antiretrovirals such as zidovudine and nevirapine, switches from patented to generic versions should save on costs without adverse consequences. However, given the potential for adverse events if these drugs are started de novo, it would not be ethical to switch patients from other drugs onto either generic zidovudine or nevirapine for cost reasons.

The potential for cost savings of generic drugs needs to be set against the potential disadvantages of pill burden and quality concerns. There is a coformulated single pill containing tenofovir, emtricitabine, and efavirenz (Atripla ${ }^{\circledR}$ ), and another combining tenofovir, emtricitabine, and rilpivirine $\left(\right.$ Eviplera $\left.^{\circledR}\right)$; there are two other single once-daily pills combining abacavir with lamivudine (Kivexa ${ }^{\circledR}$ ) and tenofovir with emtricitabine (Truvada $\left.{ }^{\circledR}\right) .{ }^{4}$ These coformulations remain patented, whereas generics are currently only available as individual antiretrovirals. However, there has not been a randomized trial comparing the use of generic antiretrovirals with patented coformulations. If a patented coformulation such as Atripla, costing $£ 7627$ per year, was compared head-to-head with a cheaper generic alternative regimens (for example, abacavir-lamivudine-nevirapine costing $£ 4085)$, the difference in efficacy between the two arms would need to be very large to justify use of the more expensive patented coformulation. Generic versions of antiretrovirals would need to meet rigorous standards of bioequivalence and drug quality to be approved for use in the UK.

Finally, the MONET, MONOI, and MONARCH trials have demonstrated the potential to save money by switching patients to darunavir-ritonavir monotherapy. ${ }^{28-30}$ However, the potential for cost savings from the use of darunavirritonavir monotherapy needs to be set against the quality of the evidence supporting this treatment strategy. The current British HIV Association guidelines and US Department of Health and Human Services guidelines do not recommend the use of protease inhibitor monotherapy, ${ }^{3,5}$ whereas the European guidelines do. ${ }^{4}$ The MONET, MONOI, and MONARCH trials did not consistently show noninferiority of darunavir-ritonavir monotherapy in the long-term. ${ }^{28-30}$ There were slightly higher rates of detection of HIV RNA in the darunavir-ritonavir monotherapy arms of these trials (although there was no evidence for a higher risk of drug resistance or for higher rates of HIV disease in the central nervous system). Similar results have been found in a systematic review of protease inhibitor monotherapy. ${ }^{32}$ A larger randomized trial of protease inhibitor monotherapy currently in progress in the UK, the Medical Research Council PIVOT (Protease Inhibitor monotherapy Versus Ongoing Triple-therapy in the long term management of HIV infection) trial, ${ }^{33}$ may provide more definitive conclusions on the efficacy of this treatment strategy. Results from this trial are expected in 2014. If using darunavir-ritonavir monotherapy before the results of the PIVOT trial are available, it is important to consider the inclusion criteria for the MONET, MONOI, and MONARCH trials. These trials all recruited patients with no history of virological failure and pretreatment nadir CD4 counts above 100 cells/uL. ${ }^{28-30}$ People with low nadir CD4 counts are at greater risk of HIV-related neurological disease, and should not be offered protease inhibitor monotherapy, since they have not been evaluated in randomized trials.

\section{Disclosure}

$\mathrm{CM}$ is an employee of Janssen Pharmaceuticals. AH has received consultancy payments from Janssen Pharmaceuticals.

\section{References}

1. House of Lords. No vaccine, no cure: HIV and AIDS in the United Kingdom. Available from: http://www.publications.parliament.uk/pa/ ld201012/ldselect/ldaids/188/188.pdf. Accessed May 30, 2012.

2. Health Protection Agency. HIV in the United Kingdom: 2011 report. Available from: http://www.hpa.org.uk/webc/HPAwebFile/ HPAweb_C/1317131685847. Accessed May 30, 2012.

3. British HIV Association. BHIVA guidelines for the treatment of adult HIV-1 infected adults with antiretroviral therapy 2012. Available from: http://www.bhiva.org/documents/Guidelines/Treatment $\% 20$ Guidelines/2012/formatted_ART_guidelines_04022012_v3_IW.pdf Accessed May 30, 2012.

4. European AIDS Clinical Society. Guidelines for the clinical management of HIV infected adults in Europe. Available from: http://www europeanaidsclinicalsociety.org/index.php?option=com_content\&vie $\mathrm{W}=$ article \&id=59\&Itemid $=41$. Accessed May 30, 2012.

5. Department of Health and Human Sciences. AIDS info. Guidelines for the use of antiretroviral agents in HIV-1-infected adults and adolescents. Available at: http://aidsinfo.nih.gov/guidelines/html/1/adultand-adolescent-treatment-guidelines/37/whats-new-in-the-guidelinesAccessed May 30, 2012.

6. Nakagawa F, Lodwick R, Smith C, et al. Projected life expectancy of people with HIV according to timing of diagnosis. AIDS. 2012;26(3): 335-343.

7. Cohen M, Chen Y, McCauley M, et al. Prevention of HIV-1 infection with early antiretroviral therapy. $N$ Engl J Med. 2011;365(6):493-505.

8. AIDS Info. Clinical Guidelines Portal. Available at: http://aidsinfo.nih. gov/Guidelines/GuidelineDetail.aspx?GuidelineID=387\&ClassID $=4$. Accessed October 21, 2011

9. Olsen $\mathrm{CH}$, Gatell J, Ledergerber B, et al. Risk of AIDS and death at given HIV-RNA and CD4 cell counts, in relation to specific antiretroviral drugs in the regimen. AIDS. 2005;19(3):319-330. 
10. The PLATO Collaboration 2004. Predictors of trend in CD4 positive T-cell count and mortality among HIV-1 infected individuals with virological failure to all three antiretroviral drug classes. Lancet. 2004;364(9492):51-62.

11. Mee P, Fielding K, Charalambous S, Churchyard GJ, Grant AD. Evaluation of the WHO criteria for antiretroviral treatment failure among adults in South Africa. AIDS. 2008;22(15):1971-1977.

12. Reynolds S, Kakigozi G, Newell K, et al. Failure of immunologic criteria to appropriately identify antiretroviral treatment failure in Uganda. AIDS. 2009;23(6):697-700.

13. Mocroft A, Phillips A, Gatell J, et al. Normalisation of CD4 counts in patients with HIV-1 infection and maximum virological suppression who are taking combination antiretroviral therapy: an observational cohort study. Lancet. 2007;370(3585):407-413.

14. Phillips A, Youle M, Lampe F, et al. CD4 cell count changes in individuals with counts above 500 cells $/ \mathrm{mm}^{3}$ and viral loads below 50 copies $/ \mathrm{mL}$ on antiretroviral therapy. AIDS. 2002;16(7): 1073-1075.

15. Chilton D, Neuhaus J, Palfreeman A. Utility of CD4 count monitoring in patients on HAART who maintain viral load suppression - experience from the VS arm of the SMART study. Abstract O21 presented at the Fourteenth British HIVAssociation Conference, April 23-25, 2008, Belfast, Ireland

16. The UK Collaborative Group on HIV Drug Resistance, UK CHIC Study Group. Long term probability of detection of HIV-1 drug resistance after starting antiretroviral therapy in routine clinical practice. AIDS. 2005;19(5):487-494.

17. Medecins Sans Frontieres. Untangling the web of antiretroviral price reductions: a pricing guide for the purchase of ARVs for developing countries. 12th ed, prepublication price analysis, July 2009. Available at: http://www.msfaccess.org/content/untangling-web-antiretroviralprice-reductions-14th-edition.

18. British National Formulary. BNF 57, March 2009. Available from: http://www.esoph.org/af/books/BNF\%2057.pdf. Accessed May 30, 2012.

19. United Pharmacies. Cost of generic $3 \mathrm{TC}$ and ZDV in the UK (60 tablets). Available from: http://www.unitedpharmacies-uk. com/3TC_150mg_60_Tablets_p_891.html. Accessed May 30, 2012.

20. Grupo de Estudio de SIDA Expert Panel and the National AIDS Plan. GESIDA consensus document/Spanish AIDS plan regarding antiretroviral treatment in adults with human immunodeficiency virus infection. Spanish. Available from: http://www.gesida.seimc.org/pcientifica/ dcconsensos.asp. Accessed May 30, 2012

21. Cost of generic nevirapine in UK. Available from: http://www.unitedpharmacies-uk.com/Nevimune_Nevirapine_200mg_10_Tablets_p_369. html.

22. Ortiz R, DeJesus E, Khanlou H, et al. Efficacy and safety of oncedaily darunavir/ritonavir versus lopinavir-ritonavir in treatment naïve HIV-1 infected patients at Week 48. AIDS. 2008;22(12):1389-1397.
23. Molina J, Andrade-Villanueva J, Echeverria J, et al. Once-daily atazanavir-ritonavir compared with twice-daily lopinavir-ritonavir, each in combination with tenofovir and emtricitabine, for management of antiretroviral-naive HIV-1 infected patients: 96 week efficacy and safety results of the CASTLE study. J Acquir Immune Defic Syndr. 2009;53(3):323-332.

24. Gallant J, DeJesus E, Arribas J, et al. Tenofovir DF, emtricitabine and efavirenz vs zidovudine, lamivudine and efavirenz for HIV. $N$ Engl $J$ Med. 2006;354(3):251-260.

25. Moyle G, Sabin C, Cartledge J, et al. A randomised comparative trial of tenofovir DF or abacavir as replacement for a thymidine analogue in persons with lipoatrophy. AIDS. 2006;20(16):2043-2050.

26. van Leth F, Phanuphak P, Ruxrungtham K, et al. Comparison of first-line antiretroviral therapy with regimens including nevirapine, efavirenz, or both drugs, plus stavudine and lamivudine: a randomised open-label trial, the 2NN Study. Lancet. 2004;363(9417):1253-1263.

27. Soriano V, Arasteh K, Migrone H, et al. Nevirapine versus atazanavir/ ritonavir each combined with tenofovir disoproxil fumarate/emtricitabine, in antiretroviral-naive HIV-1 patients : the ARTEN trial. Antivir Ther. 2011;16(3):2040-2058.

28. Arribas J, Clumeck N, Nelson M, et al. The MONET trial: week 144 analysis of efficacy of darunavir/ritonavir monotherapy versus $\mathrm{DRV} / \mathrm{r}+2 \mathrm{NRTIs}$, for patients with HIV RNA $<50$ copies $/ \mathrm{mL}$ at baseline. Abstract MOPE215 presented at the 6th International AIDS Society Conference on HIV Pathogenesis, Treatment and Prevention, July 17-20, 2011, Rome, Italy.

29. Katlama C, Valentin MA, Algarte-Genin M, et al. Efficacy of darunavir/ ritonavir as single-drug maintenance therapy in patients with HIV-1 viral suppression: a randomized open-label non-inferiority trial, MONOIANRS 136. AIDS. 2010;24(15):2365-2374.

30. Guaraldi G, Zona S, Cossarizza A, et al. Impact of switching to darunavir/ritonavir monotherapy vs triple-therapy on body fat redistribution and bone mass in virologically suppressed HIV-infected adults. The MONARCH randomized controlled trial. Abstract PE7.5/4 presented at the 13th European AIDS Conference, October 12-15, Belgrade, Serbia, 2011.

31. Gazzard B, Hill A, Anceau A. Cost-efficacy analysis of the MONET Trial using UK antiretroviral drug prices. Appl Health Econ Health Policy. 2011;9(4):217-223.

32. Bierman WF, van Agtmael MA, Nijhuis M, Danner SA, Boucher CA. HIV monotherapy with ritonavir-boosted protease inhibitors: a systematic review. AIDS. 2009;23(3):279-291.

33. UK Medical Research Council. A randomised controlled trial of a strategy of switching to boosted protease inhibitor monotherapy versus continuing combination antiretroviral therapy for the long-term management of HIV-1 infected patients who have achieved sustained virological suppression on highly-active antiretroviral therapy. Available from: http://www.controlled-trials.com/ISRCTN04857074. Accessed May 30, 2012.
ClinicoEconomics and Outcomes Research

\section{Publish your work in this journal}

ClinicoEconomics \& Outcomes Research is an international, peerreviewed open-access journal focusing on Health Technology Assessment, Pharmacoeconomics and Outcomes Research in the areas of diagnosis, medical devices, and clinical, surgical and pharmacological intervention. The economic impact of health policy and health systems

\section{Dovepress}

organization also constitute important areas of coverage. The manuscript management system is completely online and includes a very quick and fair peer-review system, which is all easy to use. Visit http://www.dovepress.com/testimonials.php to read real quotes from published authors. 